\title{
Knowledge, attitudes, and understanding of probiotics among pediatricians in different regions of Saudi Arabia
}

\author{
Mohammed Hasosah ${ }^{1 *} \mathbb{D}$, Mansour Qurashi ${ }^{2}$ Abdullah Balkhair ${ }^{3}$, Ziyad Alzahrani ${ }^{1}$, Abdullah Alabbasi ${ }^{3}$, \\ Muhanad Alzahrani ${ }^{3}$, Wejdan Alnahdi ${ }^{3}$, Sohaib Shafei ${ }^{1}$, Malak Bafaqih ${ }^{1}$ and Muhammad Khan ${ }^{3}$
}

\begin{abstract}
Background: Probiotics are live microorganisms that, when administered in adequate amounts, confer a health benefit upon the host. Knowledge and attitudes of health professionals have been reported to be at a medium level for probiotics. The objective was to evaluate the knowledge and practice styles about probiotics among pediatricians working in different regions of Saudi Arabia.
\end{abstract}

Methods: This cross-sectional study was conducted at pediatric hospitals in Saudi Arabia. A national survey of 550 pediatric providers (PPs) was conducted between January and March 2020 anonymously on their knowledge and practice styles regarding probiotics, and it was completed by pediatric residents (PRs), pediatric specialist (PSs), pediatric consultants (PCs), and pediatric gastroenterologists (PGs).

Results: The survey had a response rate of $82 \%$. Among the respondents, $57.7 \%$ were aware of the probiotic's definition. There were significant differences in the percentage of participants who had little knowledge of probiotics $(P<0.05)$, with the highest being PRs and the lowest being PGs. The most common probiotic used by all participants was Lactobacillus acidophilus (63.3\%), and Mycobacterium avium was prescribed the least often (8.6\%). Most PRs and PSs correctly reported that probiotics reduce the risk of antibiotic-induced diarrhea (74.9 and 80.2\%, respectively), but there were no significant differences among them.

Conclusions: Significant differences in knowledge and practice patterns exist for probiotics. Identification of knowledge gaps may be useful to develop educational materials to improve the proper definition, knowledge, and use of probiotics.

Keywords: Probiotics, Pediatricians, Knowledge, Attitudes

\section{Background}

The International Scientific Association for Probiotics and Prebiotics (ISAPP) published the most recent and widely accepted definition of probiotics as follows: "live microorganisms that, when administered in adequate amounts, confer a health benefit on the host" [1]. Several

\footnotetext{
* Correspondence: myhasosah@yahoo.com

'Pediatric Gastroenterology Department, College of Medicine, King Saud bin Abdulaziz University for Health Sciences, King Abdullah International Medical Research Center (KAIMRC), National Guard Hospital, Jeddah, Kingdom of Saudi Arabia

Full list of author information is available at the end of the article
}

species of the genera Bifidobacterium and Lactobacillus claim to have a core benefit on healthy gut microbiota by creating a favorable gut environment [1]. Metaanalyses also suggest that they are effective against infectious diarrhea, antibiotic-associated diarrhea, travelers' diarrhea, slow gut transit, irritable bowel syndrome, abdominal pain and bloating, and ulcerative colitis [2-4].

Probiotics are considered to be adjunction to conventional therapy along with vitamins, minerals, and other dietary supplements [5].

C C The Author(s). 2021 Open Access This article is licensed under a Creative Commons Attribution 4.0 International License, which permits use, sharing, adaptation, distribution and reproduction in any medium or format, as long as you give appropriate credit to the original author(s) and the source, provide a link to the Creative Commons licence, and indicate if changes were made. The images or other third party material in this article are included in the article's Creative Commons licence, unless indicated otherwise in a credit line to the material. If material is not included in the article's Creative Commons licence and your intended use is not permitted by statutory regulation or exceeds the permitted use, you will need to obtain permission directly from the copyright holder. To view a copy of this licence, visit http://creativecommons.org/licenses/by/4.0/ The Creative Commons Public Domain Dedication waiver (http//creativecommons.org/publicdomain/zero/1.0/) applies to the data made available in this article, unless otherwise stated in a credit line to the data. 
Today, probiotics are commercially available substances that are found in dietary supplements, drugs, functional foods, and beverages and in products such as skin creams, vaginal capsules, tampons, and chewable tablets for gum health [6]. Despite the widespread and easily accessible evidence that supports the benefits of probiotic use, health professionals may hesitate to recommend probiotics to patients when they receive conflicting messages [6]. Health professionals may have difficulties in processing large volumes of information that are generated by commercial enterprises about the benefits and use of probiotics [7].

Although there is growing global interest in the field, little is known about practicing pediatricians' perceptions regarding the use and efficacy of probiotics [7]. Information describing how often pediatricians encounter probiotic usage in their practices and their specific recommendations to their patients has not previously been reported. Knowledge of medical care providers' familiarity and opinions regarding probiotic-based treatments is essential as more patients begin to incorporate these supplements into their medical regimens and as more clinical research investigating probiotic effectiveness becomes available. Sabina et al. surveyed 1066 health professionals and reported that knowledge and attitudes of health professionals were at a medium level of knowledge for probiotics [7]. One of the assessment measures to determine the effectiveness of campaign messages is to conduct knowledge and attitudes surveys of pediatricians. Understanding the spectrum of management styles that are used in the care of children with probiotics would be paramount for improving the quality of care, having a positive effect on a child's quality of life, and achieving better health outcomes.

This is the first study in Saudi Arabia to directly assess practicing pediatricians' perceptions on the use and practice patterns for recommending probiotics in the treatment of several disorders. We aimed to investigate the current knowledge, attitude, and practice of pediatricians regarding probiotics in all regions of Saudi Arabia.

\section{Methods}

\section{Participants}

Participants were asked to complete the questionnaire if they were pediatricians. A pediatrician is defined as a physician who is involved in clinical care, research, or teaching related to pediatric medicine. Pediatricians were classified as pediatric residents (PRs), pediatric specialists (PSs), pediatric consultants (PCs), or pediatric gastroenterologists (PGs). PRs are training pediatricians while PSs are certified pediatricians. The study was conducted between January and March 2020.

\section{Study setting}

This cross-sectional national survey was conducted in the following five regions of Saudi Arabia: central region
(CR), western region (WR), eastern region (ER), northern region (NR), and southern region (SR). Saudi Arabia's population is 31 million, and children ages 0 to 14 years represent $29.4 \%$ of the population. Pediatricians working in Saudi healthcare system were from university hospitals, governmental hospitals and private hospitals. Probiotics were available over-the-counter (OTC) in Saudi Arabia in a variety of forms such as capsules, packets, or food supplements without a prescription. The survey population consisted of members listed as pediatricians by the Saudi Pediatric Association, the Saudi Commission for Health Specialties, and the Ministry of Health. These criteria resulted in an initial target cohort of approximately 4100 members. From this cohort, a random sample of 550 members was obtained.

\section{Survey design}

We designed a brief, user-friendly questionnaire that assessed the knowledge and attitudes of pediatricians regarding probiotics. The questionnaire was pilot-tested by a sample of PGs. The questionnaire was then revised based on reproducibility, validity, and question value. A group of ten pediatric gastroenterologists was evaluated in the original questionnaire, apart from the final research study (Cronbach's alpha $=0.8$ ). Reproductively, relevance and query value have been used to update this questionnaire. Changes and modifications were made based on the pilot results. The survey was administered during direct communication (interviewed face-to-face) or via email or telephone. Participants answered the English version of the questionnaire. The survey was estimated to take an average of $10 \mathrm{~min}$ to complete.

\section{Questionnaire instrument}

The questions were modeled and changed based on those used in previously published studies on the knowledge of probiotics [8]. The questionnaire consisted of 15 items in the following three subscales: demographics and practice characteristics (five items); definition and knowledge of probiotics (nine items); and source of probiotics-related information (one item). The survey includes multiple-choice questions. All questionnaire items asked participants to choose the best answer. Some response options were on the following scale: all of the time; most of the time; sometimes; seldom (rarely); or never. The datasets used and/or analyzed during the current study available from the corresponding author on reasonable request.

\section{Questionnaire subscales}

\section{Demographics and practice characteristics}

Participating pediatricians were asked for their age, title, gender, type of practice (general or subspecialty), and level of health care institutions to identify potential 
differences that may be influenced in the systematic approach to probiotics.

\section{Definition, indication, and Management of Probiotics}

Participants were asked to provide a definition of probiotics. The respondents were queried as to the most common strain of probiotics. Participants were also surveyed on how to treat infants with probiotics.

\section{Source of probiotic-related information}

Participants were asked whether they had probioticsrelated information available to them. The participants were asked about knowledge of efficacy of probiotics. The participants were asked to rank the best source of probiotics-related information that they used from a list that included medical journals, conferences, newsletters, internet, and pharmaceutical company-sponsored symposia.

\section{Statistical analysis}

Data were analyzed using SPSS PC+ version 21.0 statistical software (SPSS Inc., Chicago, IL, USA). Descriptive statistics (mean, standard deviation [SD], and percentages) were used to describe the quantitative and categorical study and outcome variables. A Pearson's Chisquare test was used to observe the association between the categorical study and outcome variables. A $P$ value of $<0.05$ was used to report the statistical significance of results.

\section{Results}

\section{Demographics}

Of the 550 questionnaires that were distributed to participating pediatricians, 452 (response rate, $82 \%$ ) were completed and analyzed. Thirteen questionnaires were excluded because of missing or incomplete data. Most of the respondents were less than 30 years of age (43.4\%), followed by those who were between 30 and 40 years of age (41.4\%), those who were between 41 and 50 years old $(7.1 \%)$, and those who were over 50 years of age (8.2\%). Our sample had equal female and male respondents 226 (50.0\%). Among them, 44\% were PRs, 23.7\% were PCs, $19.0 \%$ were PSs, and $3.1 \%$ were PGs. Respondents from government hospitals represented the highest proportion (89.6\%), followed by respondents from private hospitals (10.4\%). Demographics and practice characteristics of the study participants are presented in Table 1.

\section{Definition, indication, and Management of Probiotics}

When survey respondents were asked about the definition of probiotics, 261 of 452 respondents (57.7\%) were aware of the definition of probiotics as live microorganisms, compared with when administered in adequate
Table 1 Demographic and practice characteristics of the study participants

\begin{tabular}{|c|c|c|}
\hline Demographics & $\mathbf{n}$ & $\%$ \\
\hline \multicolumn{3}{|l|}{ Age } \\
\hline$<30$ years & 196 & 43.4 \\
\hline $30-40$ years & 187 & 41.4 \\
\hline $41-50$ years & 32 & 7.1 \\
\hline$>50$ years & 37 & 8.2 \\
\hline \multicolumn{3}{|l|}{ Gender } \\
\hline Male & 226 & 50.0 \\
\hline Female & 226 & 50.0 \\
\hline \multicolumn{3}{|c|}{ Qualification (title /position) } \\
\hline$P R$ & 199 & 44.0 \\
\hline PS & 86 & 19.0 \\
\hline ACP & 31 & 6.9 \\
\hline Ass CP & 15 & 3.3 \\
\hline $\mathrm{CP}$ & 107 & 23.7 \\
\hline$P G$ & 14 & 3.1 \\
\hline \multicolumn{3}{|l|}{ Region of practice } \\
\hline Eastern Region & 29 & 6.4 \\
\hline Western Region & 168 & 37.2 \\
\hline Central Region & 174 & 38.5 \\
\hline Northern Region & 53 & 11.7 \\
\hline Southern Region & 28 & 6.2 \\
\hline \multicolumn{3}{|l|}{ Institution } \\
\hline Government hospital & 405 & 89.6 \\
\hline Private hospital & 47 & 10.4 \\
\hline Total & 452 & 100 \\
\hline
\end{tabular}

$P R$ Pediatric resident, $P S$ Pediatric specialist, $A C P$ Assistant consultant of pediatric, Ass CP Associate consultant of pediatric, CP Consultant of pediatric, $P G$ Pediatric gastroenterologist

amounts, confer a health benefit to the host (Fig. 1). Among them, $62.8 \%$ of PRs and $48.8 \%$ of PSs reported that they have little knowledge of probiotics. However, consultants of pediatrics exhibited little knowledge of probiotics (47.7\%), while PGs showed that they have excellent knowledge regarding probiotics $(42.9 \%$; $P<$ 0.001). Correlation between responders' status and knowledge about probiotics is shown in Table 2.

There were significant differences in the percentage of participants who asked on which systems they think probiotics have an effect. Additionally, $86 \%$ of PCs reported that probiotics have effects on the GI system $(P<0.001)$. Assistant consultants (48.4\%), associate consultants (40\%), PRs (81\%), and PSs (68.6\%) reported that probiotics have effects on the GI system.

In response to questions about clinical indications for prescribing probiotics, there were no significant differences $(P=0.298)$ between them groups. However, most 


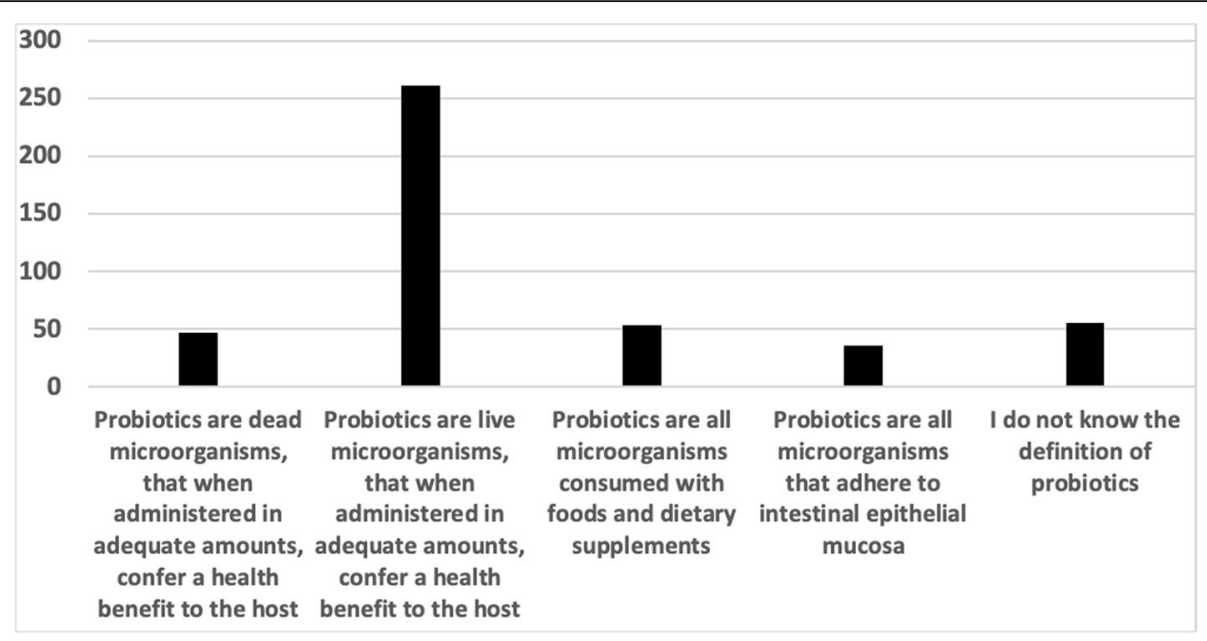

Fig. 1 Association between responders' status and definition of probiotics

participants reported that probiotics were used to improve digestion and GI immunity. Correlation between responders' status and indications of probiotics is shown (Table 3). Among the participants who responded to the survey, most PRs and PSs correctly reported that probiotics reduce the risk of antibiotic-induced diarrhea (74.9 and $80.2 \%$ ) respectively, but there were no significant differences among them.

When survey respondents were asked about the prescription of probiotics, nearly half of the participants (57.7\%) reported that probiotics must be taken before meals. Among them, $61.3 \%$ of PRs, 58.9\% of PCs, and 57.1\% PGs chose the correct answer, but there were no significant differences among them $(P=0.182)$. Association between responders' status and knowledge of probiotics is shown (Table 4).

The most common probiotic used by all participants was Lactobacillus acidophilus (63.3\%), and Mycobacterium avium was the probiotic least often prescribed (8.6\%). The lists of common probiotic strains prescribed were shown (Fig. 2). There was no significant difference in Lactobacillus rhamnosus as probiotic strain that was used by pediatricians $(P=0.840)$. Correlation between the responders' status and knowledge of probiotics is shown (Tables 3 and 4).

Regarding the source of probiotics-related information, our study showed that the sources of pediatricians' information on probiotics included the internet (50.0\%), medical journals (44.0\%), medical conferences (28.8\%), newsletters $(11.9 \%)$, and radio or TV (8.0\%).

In summary, an unanticipated finding of this study was the possible differences in probiotic use practice patterns among PS, PR, PG, ACP, and CP. Overall, the responses indicated that PR and CP were more likely to report themselves as familiar with the literature related to probiotics and the various available probiotic preparations.

\section{Discussion}

To the best of our knowledge, this was the largest study in the Middle East describing pediatricians' knowledge,

Table 2 Association between responders' status and knowledge about probiotics

\begin{tabular}{lllll}
\hline \multicolumn{7}{l}{ How is your knowledge about probiotics? } \\
\hline Qualification (title position) & $\begin{array}{l}\text { No knowledge } \\
\text { No }(\%)\end{array}$ & $\begin{array}{l}\text { Little knowledge } \\
\text { No }(\%)\end{array}$ & $\begin{array}{l}\text { Medium knowledge } \\
\text { No (\%) }\end{array}$ & $\begin{array}{l}\text { Good knowledge } \\
\text { No (\%) }\end{array}$ \\
PR & $35(17.6)$ & $125(62.8)$ & $37(18.6)$ & $2(1.0)$ \\
PS & $6(7.0)$ & $42(48.8)$ & $28(32.6)$ & $10(11.6)$ \\
ACP & $1(3.2)$ & $14(45.2)$ & $14(45.2)$ & $2(6.5)$ \\
Ass CP & $4(26.7)$ & $2(13.3)$ & $7(46.7)$ & $2(13.3)$ \\
CP & $1(0.9)$ & $51(47.7)$ & $37(34.6)$ & $18(16.8)$ \\
PG & $1(7.1)$ & $3(21.4)$ & $4(28.6)$ & $6(42.9)$ \\
Total No $(\%)$ & $48(10.6)$ & $237(52.4)$ & $127(28.1)$ & $40(8.8)$
\end{tabular}

$P R$ Pediatric resident, $P S$ Pediatric specialist, $A C P$ Assistant consultant of pediatric, Ass $C P$ Associate consultant of pediatric, $C P$ Consultant of pediatric, $P G$ Pediatric gastroenterologist 
Table 3 Association between responders' status and indications of probiotics

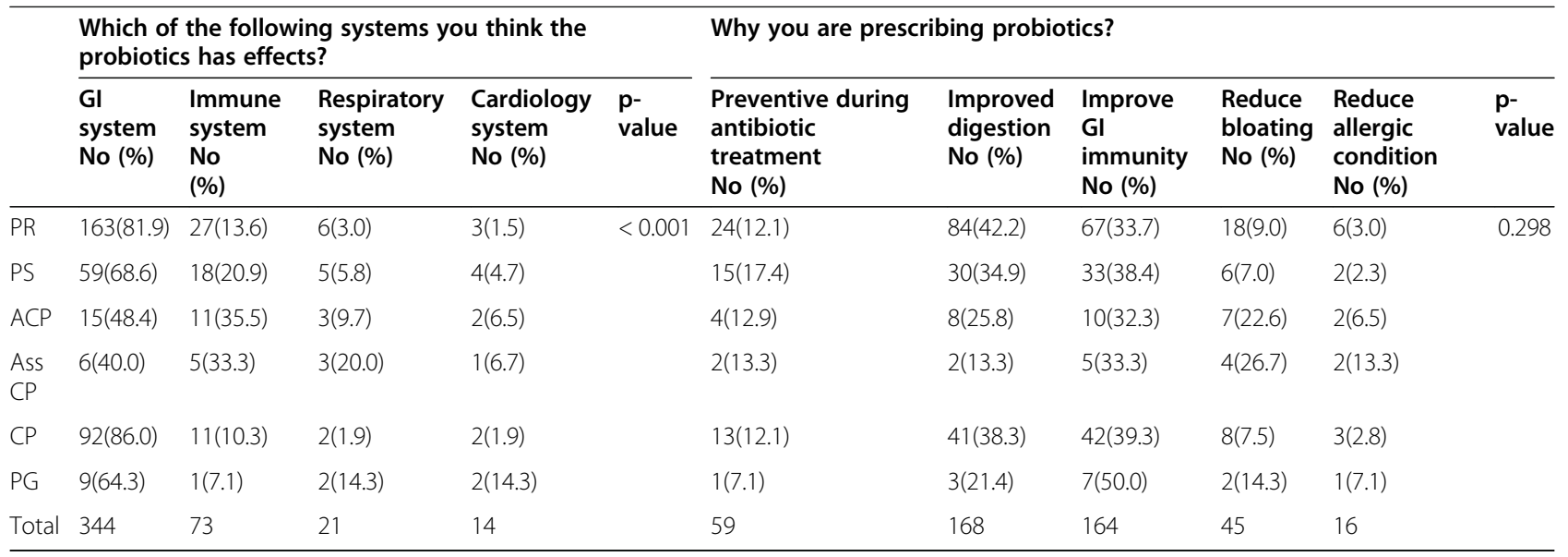

$P R$ Pediatric resident, $P S$ Pediatric specialist, $A C P$ Assistant consultant of pediatric, Ass CP Associate consultant of pediatric, $C P$ Consultant of pediatric, $P G$ Pediatric gastroenterologist

attitude, and practice regarding probiotics. Stanczak et al. surveyed 335 primary care physicians and reported that $38.5 \%$ of respondents had heard of probiotics, but only $27.2 \%$ stated that they knew what probiotics are [9]. The present study reflects that $57.7 \%$ of respondents were aware of the definition of probiotics.

In our study, it was discouraging to find that more than half of the pediatricians reported that they had little knowledge of probiotics, and significant differences in knowledge were noted between PCs from other pediatricians. These data may be explained by a lack of educational materials and different access to resources in some regions of Saudi Arabia. Together with our observation, the data demonstrated that probiotics are popular among gastroenterologists for the treatment of gastrointestinal disorders [10].

In the present study, L. acidophilus (63.3\%) was the most common probiotic used by all participants. However, Draper et al. demonstrated that Lactobacillus GG was often prescribed for general bowel health [11].
Another study showed that most surveyed physicians prescribed Bifidobacterium infantis and VSL\#3 frequently for irritable bowel syndrome and antibioticassociated diarrhea [12]. The probiotic strains belonging to the Lactobacillus and Bifidobacterium genera that are most commonly used as probiotics are well known in the literature $[13,14]$. Our observation in the present data showed that probiotic prescribing is common, but it lacks consistency, with the choice of probiotic frequently left to the patient, even for indications with some strain-specific evidence. These different kinds of probiotics that were prescribed by participants may suggest using various educational tools, including peerreviewed publications, media, seminars, and university courses to introduce the concepts and explain indications, advantages, and limitations of these probiotics.

Most of our respondents (86\%) reported that probiotics were used to improve digestion and improve gastrointestinal immunity. Similar to Williams et al. [12] 98\% of the respondents in our study believed that probiotics

Table 4 Association between responders' status and knowledge of probiotics

\begin{tabular}{|c|c|c|c|c|c|c|c|c|c|}
\hline & \multicolumn{3}{|c|}{$\begin{array}{l}\text { Do you think probiotics will reduce the risk } \\
\text { of antibiotic-induced diarrhea? }\end{array}$} & \multicolumn{3}{|c|}{$\begin{array}{l}\text { Do you think probiotics should be } \\
\text { taken before a meal? }\end{array}$} & \multicolumn{3}{|c|}{$\begin{array}{l}\text { Lactobacillus rhamnosus is the most } \\
\text { microbial species in probiotic Strains }\end{array}$} \\
\hline & $\begin{array}{l}\text { True } \\
\text { No (\%) }\end{array}$ & $\begin{array}{l}\text { False } \\
\text { No }(\%)\end{array}$ & p-value & $\begin{array}{l}\text { True } \\
\text { No }(\%)\end{array}$ & $\begin{array}{l}\text { False } \\
\text { No }(\%)\end{array}$ & p-value & $\begin{array}{l}\text { Yes } \\
\text { No }(\%)\end{array}$ & $\begin{array}{l}\text { No } \\
\text { No }(\%)\end{array}$ & p-value \\
\hline$P R$ & 149(74.9) & $50(25.1)$ & 0.270 & $122(61.3)$ & $77(38.7)$ & 0.182 & $64(32.2)$ & $135(67.8)$ & 0.840 \\
\hline PS & $69(80.2)$ & 17(19.8) & & $40(46.5)$ & $46(53.5)$ & & 28(32.6) & $58(67.4)$ & \\
\hline ACP & $18(58.1)$ & $13(41.9)$ & & $21(67.7)$ & $10(32.3)$ & & $13(41.9)$ & 18(58.1) & \\
\hline Ass CP & $10(66.7)$ & $5(33.3)$ & & $7(46.7)$ & $8(53.3)$ & & $4(26.7)$ & $11(73.3)$ & \\
\hline $\mathrm{CP}$ & 79(73.8) & $28(26.2)$ & & 63(58.9) & $44(41.1)$ & & $35(32.7)$ & $72(67.3)$ & \\
\hline PG & $10(71.4)$ & $4(28.6)$ & & $8(57.1)$ & $6(42.9)$ & & $6(42.9)$ & $8(57.1)$ & \\
\hline Total & 335 & 117 & & 261 & 191 & & 150 & 302 & \\
\hline
\end{tabular}

$P R$ Pediatric resident, $P S$ Pediatric specialist, $A C P$ Assistant consultant of pediatric, Ass $C P$ Associate consultant of pediatric, $C P$ Consultant of pediatric, $P G$ Pediatric gastroenterologist 


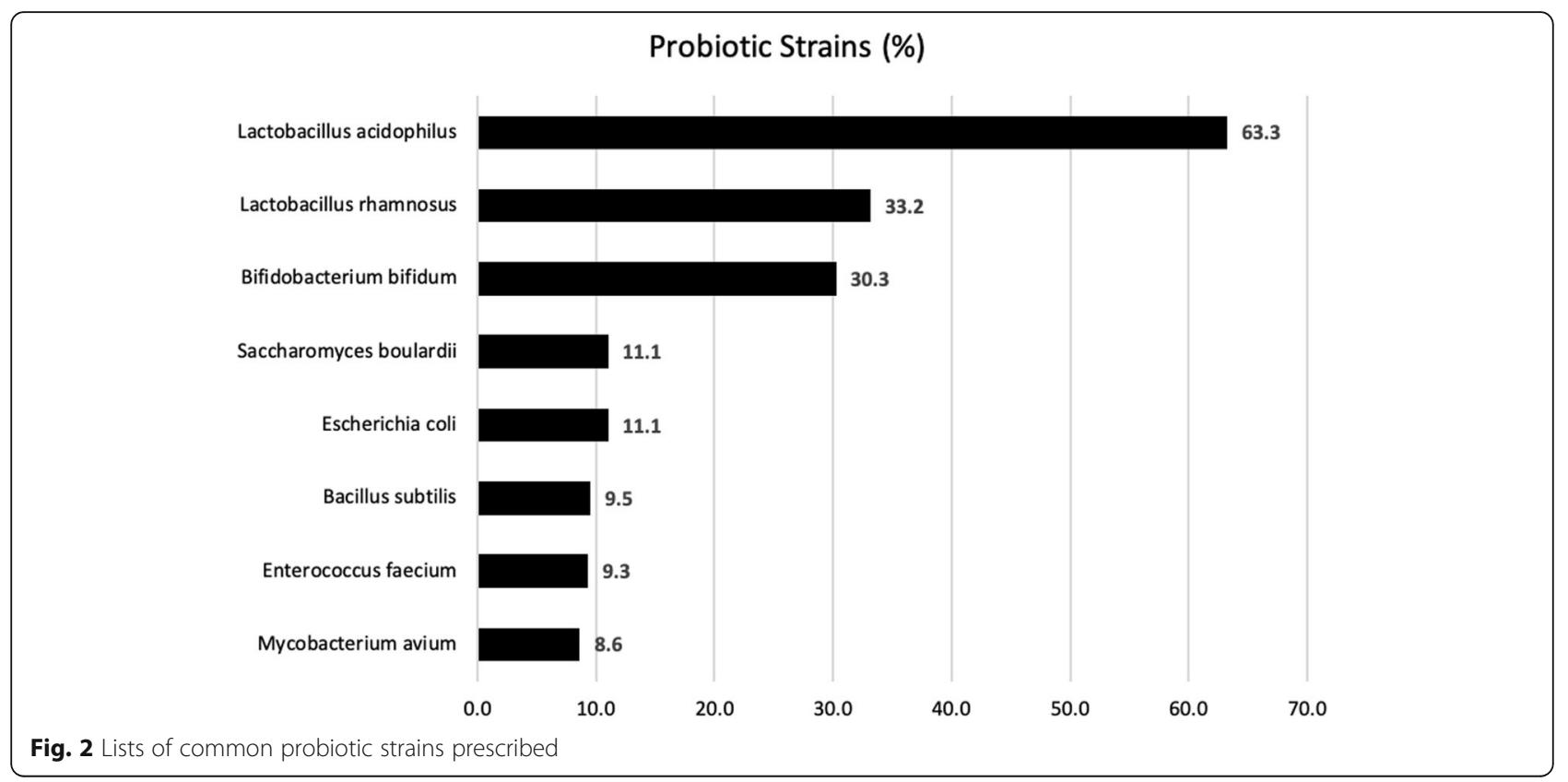

have a role in treating gastrointestinal illnesses or symptoms [12].

Thus, our participants' observations suggest that common indications for probiotics were prevention and treatment of antibiotic-associated diarrhea [11, 12]. However, many PGs worldwide do not use probiotics for acute infectious diarrhea because of a lack of appropriate guidelines and/or poorly designed products [15]. Metaanalyses have shown probiotics are well documented, and their use alone or in combination with other therapies can, therefore, be considered "evidence-based," such as for antibiotic-associated diarrhea in adults and children [16].

Several systematic reviews on adult and pediatric antibiotic-associated diarrhea (AAD) suggest that probiotic bacteria offer a solution. Data indicate that Lactobacillus strains in particular seem to be effective. The latest meta-analysis of 10 randomized control trials testing the efficacy of $\mathrm{S}$. boulardii in preventing AAD shows an overall, pooled relative risk of 0.47 \{95\% confidence interval $(\mathrm{CI})=0.35,0.63 ; p<0.001\}[16]$.

In response to the question of how respondents prescribed probiotics, most (58\%) reported that probiotics should be taken before a meal with no significant difference $P$-value among pediatricians. Similar to the observations by Tompkins et al., Sabina et al. confirmed the highest survival of probiotics if given with a meal or before a meal, and the lowest survival if taken after a meal [7, 17]. These results emphasize the importance for healthcare professionals to be properly educated and updated on probiotics because improved knowledge about probiotics would lead to increased prescriptive confidence [16].
The strengths of our study are that the study is crosssectional, the survey was conducted in all regions of Saudi Arabia, and most questionnaires were filled out under the supervision of the investigators to avoid misinterpretation of the questions. This study has several limitations. There may be some response bias-PPs who have a special interest in probiotics may have been more likely to respond to the survey. Thus, the state of knowledge of probiotics among PPs may be even lower than that reported in this study. The PR and PCs in our sample demonstrated a higher response rate than others, possibly because of more interest or more exposure to probiotics-related disorders.

In summary, our study contributed to a better understanding of probiotics in the clinical practice of Saudi pediatricians who are involved in pediatric healthcare. Effective implementation of this practice will benefit from additional supporting studies and the eventual development of clinical practice guidelines that are supported by the Saudi Gastroenterology Society.

\section{Conclusion}

This study provides valuable insight into the knowledge and practice of pediatricians working in Saudi Arabia regarding probiotics. There are significant differences in the knowledge gap and practice patterns exist among pediatricians from different regions of Saudi Arabia regarding the definition, knowledge, and use of probiotics. Identification of gaps in knowledge and practice may be helpful to policymakers who are in charge of developing educational materials for pediatricians about providing knowledge on probiotics. 


\section{Supplementary Information}

The online version contains supplementary material available at https://doi. org/10.1186/s12909-021-02499-w.

Additional file 1. Questionnaire.

\section{Abbreviations}

PPs: Pediatric providers; PRs: Pediatric residents; PSs: Pediatric specialists; PCs: Pediatric consultants; PGs: Pediatric gastroenterologists; ISAPP: International Scientific Association for Probiotics and Prebiotics

\section{Acknowledgments}

The author thanks all of the pediatric providers for participating in the survey. Special thanks to Dr. Muhammad A Khan (College of Medicine, King Saud bin Abdulaziz University for Health Sciences, Jeddah, KSA) who analyzed the results. The authors also appreciate data collectors' effort to gather the data from all the regions in Saudi Arabia.

\section{Declaration}

The authors (Mohammed Hasosah, Mansour Qurashi, Abdullah Balkhair, Ziyad Alzahrani, Abdullah Alabbasi, Muhanad Alzahrani, Wejdan Alnahdi, Sohaib Shafei, Malak Bafaqih, Muhammad Khan) declared no potential conflicts of interest with respect to the research, authorship, and/or publication of this article.

\section{Authors' contributions}

Authors' contributions MH designed the study, arranged ethics approval, collected and analysed the data and drafted the manuscript. MQ collected and analysed the data. $A B$ assisted with study design, data collection and analysis. ZA assisted with study design, data analysis and manuscript drafting AA assisted with study design and analysis. MA, WA and SS oversaw study design, ethics approval, and data analysis. MB and MK assisted with study design and data analysis. All authors read, edited for scientific accuracy, and approved the final manuscript.

\section{Funding}

The authors received no financial support for the research, authorship, and/ or publication of this article.

\section{Availability of data and materials}

Not applicable.

\section{Ethics approval and consent to participate}

The ethics committee of King Abdullah International Medical Research Center approved the study (RJ20/048/J). The recipients were considered to have consented if they filled out the questionnaire because the research presents no more than minimal risk of harm to subjects and involves no procedures. All of the information collected was kept strictly confidential.

\section{Competing interests}

Not applicable for this work

\section{Author details}

${ }^{1}$ Pediatric Gastroenterology Department, College of Medicine, King Saud bin Abdulaziz University for Health Sciences, King Abdullah International Medical Research Center (KAIMRC), National Guard Hospital, Jeddah, Kingdom of Saudi Arabia. ${ }^{2}$ Neoatology Department, College of Medicine, King Saud bin Abdulaziz University for Health Sciences, King Abdullah International Medical Research Center (KAIMRC), National Guard Hospital, Jeddah, Kingdom of Saudi Arabia. ${ }^{3}$ Pediatric Department, College of Medicine, King Saud bin Abdulaziz University for Health Sciences, King Abdullah International Medical Research Center (KAIMRC), National Guard Hospital, PO Box: 8202, Jeddah 21482, Kingdom of Saudi Arabia.

Received: 8 August 2020 Accepted: 13 January 2021

Published online: 21 January 2021

\section{References}

1. Hill C, Guarner F, Reid G, Gibson GR. The international scientific Association for Probiotics and Prebiotics consensus statement on the scope and appropriate use of the term probiotic. Nat Rev Gastroenterol Hepatol. 2014; 11:506-14.

2. Goldenberg JZ, Yap C, Lytvyn L, et al. Probiotics for the prevention of Clostridium difficile-associated diarrhea in adults and children: a systemic review and meta-analysis. Cochrane Database Syst Rev. 2017;12:CD006095.

3. Ritchie ML, Romanuk TN. A meta-analysis of probiotic efficacy for gastrointestinal diseases. PLoS One. 2012;7:e34938.

4. Agamennone V, Krul CAM, Rijkers G. A practical guide for probiotics applied to the case of antibiotic-associated diarrhea in The Netherlands. BMC Gastroenterol. 2018;18:103.

5. April KT, Moher D, Stinson J. Measurement properties of questionnaires assessing complementary and alternative medicine use in pediatrics: a systematic review. PLoS One. 2012;7:e39611.

6. Vecchione A, Celandroni F, Mazzantini D, et al. Compositional quality and potential gastrointestinal behavior of probiotic products commercialized in Italy. Front Med. 2018;5:59

7. Fijan S, Frauwallner A, Varga L, et al. Health Professionals' Knowledge of Probiotics: An International Survey. Int J Environ Res Public Health. 2019; 16(17):3128.

8. Soni R, Tank K, Jain N. Knowledge, attitude and practice of health professionals about probiotic use in Ahmedabad, India. Nutr Food Sci. 2018; 48:125-35.

9. Stanczak M, Heuberger R. Assessment of the knowledge and beliefs regarding probiotic use. Am J Health Educ. 2009:40:207-11.

10. Cordina C, Shaikh I, Shrestha S, et al. Probiotics in the management of gastrointestinal disease: analysis of the attitudes and prescribing practices of gastroenterologists and surgeons. J Dig Dis. 2011;12(6):489-96.

11. Draper K, Ley C, Parsonnet J. Probiotic guidelines and physician practice: a cross-sectional survey and overview of the literature. Benef Microbes. 2017; 8(4):507-19.

12. Williams MD, Ha CY, Ciorba MA. Probiotics as therapy in gastroenterology: a study of physician opinions and recommendations. J Clin Gastroenterol. 2010:44(9):631-6.

13. Fijan S. Microorganisms with claimed probiotic properties: an overview of recent literature. Int J Environ Res Public Health. 2014;11:4745-67.

14. Pandey KR, Naik SR, Vakil BV. Probiotics, prebiotics and synbiotics-a review. J Food Sci Technol. 2015:52:7577-87.

15. Weizman Z. Probiotics use in childhood acute diarrhea: a web-based survey J Clin Gastroenterol. 2011;45(5):426-8.

16. Rondanelli M, Faliva MA, Perna S. Using probiotics in clinical practice: Where are we now? A review of existing meta-analyses. Gut Microbes. 2017;8(6): $521-43$.

17. Tompkins T, Mainville I, Arcand Y. The impact of meals on a probiotic during transit through a model of the human upper gastrointestinal tract. Benef Microbes. 2011;2:295-303.

\section{Publisher's Note}

Springer Nature remains neutral with regard to jurisdictional claims in published maps and institutional affiliations.

\section{Ready to submit your research? Choose BMC and benefit from:}

- fast, convenient online submission

- thorough peer review by experienced researchers in your field

- rapid publication on acceptance

- support for research data, including large and complex data types

- gold Open Access which fosters wider collaboration and increased citations

- maximum visibility for your research: over $100 \mathrm{M}$ website views per year

At $B M C$, research is always in progress.

Learn more biomedcentral.com/submission 